\title{
Optimal design of intensified processes for DME synthesis
}

DOI:

10.1016/j.compchemeng.2017.01.004

\section{Document Version}

Accepted author manuscript

Link to publication record in Manchester Research Explorer

\section{Citation for published version (APA):}

Bîldea, C. S., Gyrgy, R., Brunchi, C. C., \& Kiss, A. A. (2017). Optimal design of intensified processes for DME synthesis. Computers and Chemical Engineering, 105, 142-151.

https://doi.org/10.1016/j.compchemeng.2017.01.004

\section{Published in:}

Computers and Chemical Engineering

\section{Citing this paper}

Please note that where the full-text provided on Manchester Research Explorer is the Author Accepted Manuscript or Proof version this may differ from the final Published version. If citing, it is advised that you check and use the publisher's definitive version.

\section{General rights}

Copyright and moral rights for the publications made accessible in the Research Explorer are retained by the authors and/or other copyright owners and it is a condition of accessing publications that users recognise and abide by the legal requirements associated with these rights.

\section{Takedown policy}

If you believe that this document breaches copyright please refer to the University of Manchester's Takedown Procedures [http://man.ac.uk/04Y6Bo] or contact uml.scholarlycommunications@manchester.ac.uk providing relevant details, so we can investigate your claim.

\section{OPEN ACCESS}




\section{Optimal design of intensified processes for DME synthesis}

3 Costin Sorin Bîldea, ${ }^{1}$ Romuald György, ${ }^{2}$ Cristian C. Brunchi, ${ }^{3}$ Anton A. Kiss ${ }^{4,5}$

$4{ }^{1}$ University "Politehnica” of Bucharest, Polizu 1-7, 011061 Bucharest, Romania

$5 \quad{ }^{2}$ Aristotle University of Thessaloniki, Department of Chemical Engineering, Greece

$6{ }^{3}$ Delft University of Technology, Process \& Energy Department, Leeghwaterstraat 34, 2628

$7 \quad$ CA Delft, The Netherlands

$8{ }^{4}$ AkzoNobel Research, Development \& Innovation, Process Technology SRG, Zutphenseweg

9 10,7418 AJ Deventer, The Netherlands.E-mail:Tony.Kiss@akzonobel.com

$10{ }^{5}$ Sustainable Process Technology Group, Faculty of Science and Technology, University of

11 Twente, PO Box 217, 7500 AE Enschede, The Netherlands

\section{Keywords}

Dimethyl ether, gas-phase reactor, reactive distillation, process design, process optimization

\section{5}

\section{Highlights}

- Rigorous design and simulation of gas-phase and reactive distillation DME processes

- Reactive distillation is suitable for new DME plants due to lowest CapEx and OpEx

- Existing plants can be revamped to gas-phase reactor coupled with reactive distillation

\section{Abstract}

Dimethyl ether (DME) is widely used as green aerosol propellant, precursor to other organic compounds, or as a clean fuel for diesel engines or in combustion cells. The classic method for producing DME is by dehydration of methanol in a catalytic gas-phase reactor, and purification in a direct sequence of two distillation columns. Reactive distillation (RD) is a much better alternative for DME synthesis, based on process intensification principles.

This paper presents the optimal design of novel DME processes based on reactive distillation, and makes a fair comparison with the classic reactor-separation-recycle process (for a plant capacity of 100 ktpy DME). The new RD processes were optimized in terms of minimizing the total annual costs, leading to savings of $30 \%$ in CapEx and 6\% in energy requirements for the RD process. The results indicate that a RD column is recommended for new DME plants, while a combination of gas-phase reactor and RD is suitable for revamping existing plants. 


\section{Introduction}

2 Dimethyl ether (DME) has remarkable properties (e.g. non-toxic colorless gas, non-corrosive, non-carcinogenic, environmentally friendly) that make it usable as green aerosol propellant, as precursor to organic compounds, and as clean fuel for diesel engines or combustion cells (Muller and Hubsch, 2005). It is worth noting that DME market is estimated to worth 9.7 billion USD by 2020 (www.marketsandmarkets.com). Many of the current industrial DME plants are based on the methanol dehydration route - in a conventional reactor-separation-recycle process (Kiss et al., 2007; Dimian et al., 2014) whereas methanol can be produced from (bio-based) syngas or by $\mathrm{CO}_{2}$ hydrogenation (Kiss et al., 2016). The chemical recycling of carbon dioxide to methanol and dimethyl ether has been advocated by Olah et al. (2009) and it plays a key role in a methanol economy. Unexpectedly, there are only few references in literature related to the design and economic evaluation of an entire process for DME synthesis. Lei et al. (2011) discuss the economics of a process consisting of a fixed-bed reactor and two ordinary distillation columns. Nevertheless, the reactor is modeled as a simple Gibbs reactor where equilibrium is attained. The recycle of unreacted methanol was not considered, neither the issues related to heating of the reactant, cooling the reactor effluent, or heat-integration. Bai et al (2013) presented the simulation of a process for DME synthesis by vapor phase methanol dehydration in a fixedbed adiabatic reactor, with 1000 ktpy production rate. The simulation model is also compared to data acquired from a set of industrial production equipment with a capacity of $200 \mathrm{ktpy}$. An industrial solid acidic catalyst was used, and the kinetic model was developed by the same authors (Li et al, 2009). A follow-up paper (Bai et al., 2014) mentions a five-bed industrial reactor, operated adiabatically and provided with heat-exchangers for inter-stage cooling. They also present detailed simulation results for a three-bed adiabatic reactor where interstage cooling is achieved by injecting (a fraction of) the fresh, reactor cold feed. Farsi et al. (2010) used a genetic algorithm to find the temperature distribution in a multi-tubular reactor which maximizes the DME production rate. Compared to the conventional adiabatic reactor, the methanol conversion increases from $81.9 \%$ to $85.75 \%$ which results in $4.3 \%$ increase of DME production rate. However, this is achieved at the cost of a more complex reactor. The authors also remark that the optimal temperature profile is difficult to be obtained in practice. None of the above-mentioned papers (Bai et al., 2014, Farsi et al., 2010) discuss the positive impact that the more complex reactor setup has on the plant profitability. Han et al (2009) presented the simulation of a one-step process for DME production in a slurry reactor, from coal-based syngas (66.25 ktpy production rate). A simple CSTR model was used, after 
1 verification on a set of experimental data obtained on a laboratory-scale reactor fed with 0.93 $\mathrm{mol} / \mathrm{h}$ syngas.

3 To increase the capacity of DME production, the chemical industry needs novel eco-efficient 4 processes that can meet the growing market demand (Arcoumanis et al., 2008; Azizi et al., 2014). The suggested improvements of the methanol dehydration process followed a number of technologies reported in literature: fully thermally-coupled distillation columns (Petlyuk) or dividing-wall column replacing the direct distillation sequence (Kiss, 2013; Kiss and Ignat, 2013); self-heat recuperation (Kansha et al., 2015); simultaneous synthesis and separation in a catalytic distillation process (An et al., 2004; Lei et al., 2011); catalytic cyclic distillation (Patrut et al., 2014); or reactive dividing-wall column (Kiss and Suszwalak, 2012). Additional DME technologies (e.g. coupled and dual type reactors, micro-reactors, membrane reactors, and spherical reactors), including the direct route from syngas, are also well described in the review paper of Azizi et al. (2014). Among these technologies, reactive distillation (RD) seems to be the most promising (Azizi et al, 2014), being a proven process intensification method that effectively combines the reaction and separation into a single unit (Agreda et al., 1990). RD can considerably improve the performances of an equilibrium limited process, by pulling the conversion to completion (thus avoiding recycles), increasing selectivity and productivity, reducing the energy use, and overall reducing the CapEx and OpEx (Huss et al., 1999, Malone et al., 2003; Schoenmakers and Bessling, 2003; Sundmacher and Kienle, 2003; Harmsen, 2010; Kiss and Bildea, 2012). This study is the first to provide the optimal design of novel DME processes based on reactive distillation, one process (single RD column) being most suitable for new DME plants, and another one (coupling a gas-phase reactor and a RD column) that is more appropriate for revamping existing DME plants based on gas-phase methanol dehydration. These novel process alternatives are optimized in term of minimum total annual costs (TAC) and compared to the classic reactor-separation-recycle process (at a capacity of $100 \mathrm{ktpy} \mathrm{DME}$, over $99.99 \%$ purity), in terms of key performance indicators (e.g. CapEx, OpEx, and specific energy usage). Rigorous design and simulations were performed in Aspen Plus, including accurate LHHW kinetics for both the gas-phase and liquid-phase reactions as well as rigorous phase equilibrium calculations.

\section{Problem statement}

33 Due to the ever increasing demand in cheap chemicals and alternative fuels, the industry 34 strives to deliver DME at even lower costs using the current plants (optimized and revamped) 
1 or new plants based on process intensification technologies. Most of the DME technologies described in literature (Azizi et al., 2014) are hindered by the incomplete conversion of methanol which requires costly downstream processing, recovery and large recycle of methanol (up to $40 \%$ of the fresh methanol feed). To solve this problem, this study proposes DME process alternatives based on reactive distillation, which allows the complete conversion of methanol (and avoids recycle streams) at competitive costs.

\section{Simulation approach}

Rigorous simulations were performed in Aspen Plus for each of the process alternatives investigated in this study, considering a plant capacity of 100 ktpy DME. This section provides details on the thermodynamics and kinetic parameters, as well as the methodology used for the process optimization (i.e. minimization of the total annual costs) and economic evaluation (e.g. estimation of capital and operating expenditures).

\subsection{Physical properties}

The non-ideality of the liquid phase was modeled using the UNIQUAC liquid activity model. The methanol-water and methanol-DME binary interaction parameters are available in the Aspen Plus database, while the water-DME binary interaction parameters were taken from the NIST database. The non-ideality of the vapor phase was modeled by the Redlich-Kwong equation of state. Redlich-Kwong EOS requires critical properties of the pure components, which are also available in the Aspen Plus database. The property model was also validated against experimental data reported in literature (Teodorescu and Rasmussen, 2001; Ihmels and Lemmon, 2007; Wu et al, 2011). Figure 1 shows the residue curves map (RCM) and the ternary map of the DME-methanol-water mixture (Kiss and Suszwalak, 2012). There are no azeotropes present in this system, but there is a small region where phase splitting is possible.

\subsection{Reaction kinetics}

DME is formed in the reversible chemical reaction of methanol dehydration, either in gasphase (catalyzed by $\gamma$-alumina) or in liquid-phase (catalyzed by ion exchange resins).

$$
2 \mathrm{CH}_{3} \mathrm{OH} \rightleftarrows \mathrm{CH}_{3} \mathrm{OCH}_{3}+\mathrm{H}_{2} \mathrm{O}
$$

2 Gas-phase reaction. The reaction rate of the gas phase methanol dehydration, on a 3 commercial $\gamma-\mathrm{Al}_{2} \mathrm{O}_{3}$ catalyst, was described by the following kinetics. The apparent kinetic 
1 parameters provided by Berčič and Levec (1993) were used (the original apparent rate constant $k_{\mathrm{s}}$ was increased by a factor 100 , in order to match the effectiveness factor presented

3 in the same paper). Other similar kinetics are reported in literature (Mollavali et al., 2008).

$4 r=\frac{k_{s} K_{M}^{2}\left(y_{M}^{2}-\frac{y_{W} y_{D}}{K_{e q}}\right)}{\left(1+2 \sqrt{K_{M} y_{M}}+K_{W} y_{W}\right)^{4}}$

5 With the following constants:

$6 \quad k_{\mathrm{s}}=3.30 \times 10^{9} \exp (-10800 / T), \mathrm{kmol} /(\mathrm{kg} \cdot \mathrm{h})$

$7 \quad K_{\mathrm{M}}=0.72 \times 10^{-2} \exp (830 / T)$, dimensionless

$8 \quad K_{\mathrm{W}}=0.45 \times 10^{-2} \exp (1130 / T)$, dimensionless

9 The equilibrium constant $K_{\text {eq }}$ was calculated (by Aspen Plus) from Gibbs free energies.

11 Liquid-phase reaction. The reaction rate of the liquid phase methanol dehydration on 12 Amberlyst-35 was described by the following rate equation - using the kinetic parameters from Hosseninejad et al. (2012):

$$
r=\frac{k_{s}}{\left(1+\frac{K_{W} c_{W}}{K_{M} c_{M}}\right)^{2}}\left(1-\frac{1}{K_{e q}} \frac{c_{D} c_{W}}{c_{M}^{2}}\right)
$$

With the following constants:

$k_{\mathrm{s}}=6.12 \times 10^{9} \exp (-11793 / T), \mathrm{kmol} /(\mathrm{kg} \cdot \mathrm{s})$

$K_{\mathrm{W}} / K_{\mathrm{M}}=\exp (-6.46+2964.0 / T)$

$K_{\text {eq }}=\exp (-2.6305+2787 / T)$, regressed from equilibrium constant $\left(K_{\text {eq }}\right)$ values calculated by

Aspen Plus from Gibbs free energies.

\subsection{Optimization and economics}

Optimizing a chemical process is usually a mixed-integer nonlinear problem that is nonconvex and likely to have multiple locally optimal solutions. Hence a guarantee of convergence to the globally optimal solution is not possible for non-convex problems. More details about the decision variables, constrains and solution method are provided later, within the appropriate context. In this work, each process design is optimized using the minimization of the total annual cost (TAC) as objective function: 
1 A payback period of 3 years was used, and a running time of 8000 hours/year was considered.

2 The following heating and cooling costs were taken into account: high-pressure (HP) steam

3 (42 bar, $\left.254{ }^{\circ} \mathrm{C}, \$ 9.88 / \mathrm{GJ}\right)$, medium-pressure (MP) steam (11 bar, $\left.184{ }^{\circ} \mathrm{C}, \$ 8.22 / \mathrm{GJ}\right)$, lowpressure (LP) steam $\left(6\right.$ bar, $\left.160{ }^{\circ} \mathrm{C}, \$ 7.78 / \mathrm{GJ}\right)$, and cooling water $(\$ 0.72 / \mathrm{GJ})$. These costs of utilities are typical for a US plant (Luyben, 2011), but they might differ for other locations. The total investment costs (CapEx) include the reactor, all heat exchangers, and distillation columns. The cost of the heat exchangers (reboiler, condenser, FEHE, steam generator, cooler) are given by (Turton et al., 2009):

$C_{H E X}(U S \$)=(M \& S / 280) \cdot\left(474.7 \cdot A^{0.65}\right)\left(2.29+F_{m}\left(F_{d}+F_{p}\right)\right)$

$C_{\text {furnace }}(U S \$)=(M \& S / 280) \cdot\left(15668 \cdot Q^{0.85}\right)\left(1.27+F_{c}\right)$

where $M \& S$ is the Marshall $\&$ Swift equipment cost index $(M \& S=1536.5$ in 2012), $A$ is the area $\left(\mathrm{m}^{2}\right), F_{m}=1$ (carbon steel), $F_{d}=0.8$ (fixed-tube), $F_{p}=0$ (less than 20 bar). A heat transfer coefficient $U=0.5 \mathrm{~kW} / \mathrm{m}^{2} / \mathrm{K}$ was assumed to calculate the heat transfer area. For the reboilers, the design factor was taken as $F_{d}=1.35$. For the furnace, $Q$ is the duty (in $\mathrm{MW}$ ), while the correction factor was taken as $F_{c}=1$ (process heater, carbon steel, design pressure less than 40 bar).

The distillation columns diameter $(D)$ were obtained by the tray sizing utility from Aspen Plus, while the height was evaluated from the number of trays $(N T)$, as: $H=0.6 \cdot(N T-1)+2$ (m). Afterwards, the cost of the columns shell was calculated as:

$C_{\text {shell }}(U S \$)=(M \& S / 280) \cdot\left(957.9 \cdot D^{1.066} \cdot H^{0.82}\right) \cdot\left(2.18+F_{c}\right)$

The cost of the trays was given by (Turton et al., 2009):

$C_{\text {trays }}(U S \$)=N T \cdot(M \& S / 280) \cdot 97.2 \cdot D^{1.55} \cdot\left(F_{t}+F_{m}\right)$

with $F_{t}=0$ (sieve trays) and $F_{m}=1$ (carbon steel)

where $F_{\mathrm{c}}=F_{m} \cdot F_{p}, F_{m}=1$ (carbon steel) and $F_{p}=1+0.0074 \cdot(P-3.48)+0.00023 \cdot(P-3.48)^{2}$

The price of the structured packing (KATAPAK-SP 11) was taken as $10,000 \$ / \mathrm{m}^{3}$. The relationship (7) was also used to estimate the cost of the tubular reactor. For the solid acid catalyst (Amberlyst-35 ion exchange resin, with a bulk density of $560 \mathrm{~kg} / \mathrm{m}^{3}$ ) and the gasphase catalyst ( $\gamma$-alumina, bulk density $882 \mathrm{~kg} / \mathrm{m}^{3}$, particle size $3 \mathrm{~mm}$ ), a purchased cost of 10 $\$ / \mathrm{kg}$ was considered. Clearly, the price of catalyst differs per country and manufacturer. 


\section{Results and discussion}

This section provides the simulation results for the three DME process options considered: reactor-separation-recycle (R-S-R) process, single step process using a reactive distillation column, and combined gas-phase reactor and reactive distillation process.

\subsection{Reactor-separator-recycle process}

In the conventional R-S-R process, methanol is dehydrated over a $\gamma$-alumina catalyst (or HZSM-5, silica-alumina, phosphorous-alumina and fluorinated-alumina) to produce DME. The fixed-bed gas-phase reactor is operated at $250-400^{\circ} \mathrm{C}$ and pressure up to 20 bars. Due to incomplete conversion, a direct sequence of two distillation columns is required to deliver high-purity (min. 99.99 \%wt) DME (Muller and Hubsch, 2005; Kiss and Ignat, 2013).

Figure 2 shows the process flowsheet, mass balance and the key design parameters of the reactor-separation-recycle process for DME production. The fresh methanol feed is mixed with the recycled methanol stream and fed via a feed-effluent heat exchanger (FEHE) to a furnace, which vaporizes the whole stream. Methanol vapor is converted in the reactor to DME and water, but the conversion is incomplete. The hot reactor outlet stream is used in FEHE to pre-heat the feed to the reactor, and then the remaining heat of the hot stream is used for steam generation (which can be used for the reboiler of methanol recovery column). The outlet of the steam generator is fed directly, as vapor, to the DME distillation column (COL-1). Note that further cooling to liquid at boiling point (about $64{ }^{\circ} \mathrm{C}$ ) increases the TAC, as an additional heat exchanger is needed and transferring the heat to cooling water increases the duty required for DME separation. In COL-1, the DME is separated as top distillate, while the bottom product (mixture of methanol and water) is fed to the methanol recovery column (COL-2), which separates methanol as distillate (a stream that is recycled in the process) and water by-product as bottom stream.

For the conventional process, the choice of the reactor is a major design decision, as it determines the achievable conversion. In general, approaching the chemical equilibrium condition has a beneficial effect on the TAC, as the cost reduction of the separation section (CapEx and OpEx) overcome the expense of using more catalyst.

When a single-bed adiabatic reactor is used, the design decisions concern the reactor size (diameter and length) and the reactor-inlet temperature. The diameter was calculated by imposing a fluid velocity $u=0.25 \mathrm{~m} / \mathrm{s}$, which is in line with the reported value of an industrial DME reactor (Bai et al, 2013). Note that a high velocity (> $2 \mathrm{~m} / \mathrm{s}$ ) results in (unpractical) high pressure drop while a lower velocity decreases the mass transfer rate from the fluid to the 
1 solid catalyst particle. Concerning the reactor length, a longer reactor (more catalyst) leads to higher conversion and thus reduces the separation costs, but pressure drop increases and the reactor is more difficult to build and operate. A higher feed temperature increases the reaction rate and therefore reduces the amount of catalyst required to achieve a certain conversion. On the other hand, more heat is required and the achievable conversion is reduced due to the exothermal nature of the chemical reaction. Moreover, the temperature along the reactor bed is increased, with negative effect on catalyst stability. Figure 3 presents the TAC versus inlet temperature, for reactors with different lengths. For each reactor, the optimal operating point (minimum plant TAC) is marked, together with the values of the total annual cost, TAC ${ }^{*}$, total investment cost $\mathrm{TIC}^{*}$, total operating cost $\mathrm{TOC}^{*}$, pressure drop along the reactor, $\Delta P$, and maximum temperature along the reactor bed, $T_{\text {out }}$. It can be observed that the reactor leading to minimum TAC while fulfilling the constraint of outlet temperature below $400 \mathrm{C}$ (when the catalyst starts to deactivate) has the $12 \mathrm{~m}$ length, being fed at $275^{\circ} \mathrm{C}$. This will be considered for further comparison with other design alternatives.

Figure 4 presents lines of constant reaction rate in the temperature - conversion plane. The line of maximum reaction rate (at a given conversion) is represented by the dashed line. Also, the figure shows the reaction trajectories corresponding to reactors of length $8 \mathrm{~m}, 12 \mathrm{~m}$ and 16 $\mathrm{m}$, fed at the optimum temperature. It can be noticed that all the optimal reactors approach the equilibrium, therefore the reduction of separation costs exceeds the cost of using more catalysts.

While evaluating the TAC shown in Figure 3, the performance of the distillation columns was specified in terms of distillate purity (99.99\%wt DME, COL-1) and bottoms purity (>99.95 \%wt water, COL-2). The usual design condition of $R=1.2 R_{\min }$ (Luyben, 2011) was used, while the location of the feed tray was chosen such that the minimum reboiler duty is achieved. The specification for the methanol recycle purity (in the range $0.95 \%$ wt to 0.999 $\%$ wt) had little influence on the optimal reactor design and minimum TAC value. The DME column (COL-1) was operated at 10 bar, which allows use of cooling water in the condenser. The FEHE increases the temperature of the reactor feed stream up to $140{ }^{\circ} \mathrm{C}$, by using the reactor effluent as heat source. Note that the amount of heat that can be recovered in the FEHE is limited by the temperature crossover which occurs when higher outlet temperature of the cold stream is specified (Figure 5).

Table 1 and Table 2 list the simulation results of the R-S-R process for DME production, while Table 3 provides a summary of the economic results. Note that the furnace contributes by $29 \%$ to CapEx and $61 \%$ to OpEx, so heat-recovery (using FEHE, steam generation and 
1 vapour feed to the DME column) plays an important role in the process. The specific energy requirements are $2.58 \mathrm{MJ} / \mathrm{kg}(714 \mathrm{kWh} / \mathrm{ton}) \mathrm{DME}$.

\subsection{Reactive distillation process}

$\mathrm{RD}$ conveniently combines reaction and separation in a single unit that can drive conversion to completion by continuously removing the products from the system. In such processes, designing a RD column at the maximum driving force results in an optimal design in terms of controllability and operability, which is less sensitive to disturbances in the feed and has the inherent ability to reject disturbances (Mansouri et al., 2015).

As shown in Figure 6, methanol is fed at the top of the reactive zone in the RD column (on stage 9). The reaction takes place in the reactive zone where the solid acid catalyst is placed (stages 9-42). DME is the lightest component in the system hence removed as top distillate, while water is the heaviest component hence removed as bottoms. Unlike the gas-phase reaction, the dehydration of methanol in liquid phase is catalyzed by thermally stable resins, such as Amberlyst-35 which has high activity and selectivity at temperatures up to $150{ }^{\circ} \mathrm{C}$. The design of RD processes can be performed using single and multi-objective optimization approaches (Segovia-Hernandez et al., 2015). The optimal design of the RD process (and the next one using reactive distillation) is a mixed-integer nonlinear problem (MINLP). Such problems are intrinsically very difficult to solve, and the solution time increases rapidly with the number of variables and constraints.

21 The decision variables used in the optimization are the following:

- Discrete (integers): number of stages $(N T)$, feed stage $(N F)$, reactive stages $\left(N R_{1}-N R_{2}\right)$

- Continuous (real numbers): reflux ratio $(R R)$, pressure $(P)$, amount of catalyst / tray $\left(m_{\text {cat }}\right)$

The optimization considers the following constraints:

- Distillate purity: $99.99 \%$ wt DME

- Bottoms purity: exceeding $99.95 \%$ wt

- Temperature on the reactive stages: below $150{ }^{\circ} \mathrm{C}$ (to avoid catalyst deactivation)

- Catalyst must fit into the available space (no more than $20 \%$ of the packing volume)

Note that the optimal steady state operating point is often defined by the intersection of active constraints (Kookos and Perkins, 2016). This well-established feature of chemical processes is neatly exploited to simplify the solution of the optimization problem. Thus, the RD column for DME synthesis has the following features, confirmed by several sensitivity analysis runs:

- When the distillate rate is set to half of the feed (based on reaction stoichiometry), due to 
the relative volatilities of the species involved in the process, methanol is equally distributed between the distillate and the product streams. Therefore, achieving $99.99 \% \mathrm{wt}$ distillate purity (DME) by manipulating the reflux ratio also ensures that the purity of the bottoms stream (water) exceeds the $99.95 \%$ wt requirement.

- The operating costs (OpEx) represent more than $75 \%$ of the TAC. The main contributions to the capital costs (CapEx) are the condenser, reboiler, column shell and structured packing, with the catalyst representing less than 3\%. For this reason, increasing the amount of catalyst per theoretical stage invariably results in a lower value of the TAC, as the reduction of the other costs clearly outweighs the cost of catalyst. However, the amount of catalyst is limited to $20 \%$ of the available volume (Götze et al., 2001).

- Increasing the operating pressure leads to higher temperature along the RD column. This results in faster reaction rates and, in turn, to lower TAC due to reduced effort necessary to achieve the separation. Therefore, the optimal pressure leads to the highest allowable temperature in the reactive section.

Based on these observations, the following optimization strategy is employed. In Aspen Plus, set the discrete decision variables: number of stages, feed stage, and reactive stages. The distillate molar rate is set to half of the feed, according to reaction stoichiometry. By means of Design Specification blocks, the continuous decision variables (reflux ratio, pressure, and amount of catalyst on each tray) are adjusted such that the constraints are fulfilled (distillate purity $99.99 \%$ wt DME; temperature on reactive stages $<150{ }^{\circ} \mathrm{C}$; catalyst fits into the available space of $20 \%$ of the packing volume). Due to mass balance and high purity of the distillate, the purity of the bottoms stream always exceeds the $99.95 \%$ wt requirement. The simulation is run and the value of the TAC is obtained. Afterwards the discrete variables are adjusted, and new runs are performed, until the minimum TAC is obtained. In this work, the optimal values of the discrete variables are found using the genetic algorithm implemented in Matlab by means of the $g a$ function. The user-provided Matlab objective function uses the COM interface to communicate with Aspen Plus: sends to Aspen Plus the values of the discrete decision variables, requests the simulation run and checks the convergence. After a successful run, the objective function (TAC, calculated in Aspen Plus by a FORTRAN Calculator block) and the continuous decision variables (obtained by the Design Specification blocks) are retrieved and saved in an Excel file together with the discrete decision variables. Then, the value of the objective function is passed to the $g a$ function, which performs a new iteration. If Aspen Plus simulation does not converge, the simulation is re-initialized and a new run is attempted. If this also fails, a large value is returned to $g a$ as the value of the 
1 objective function. During an initial run, rather large ranges of the discrete variables were assumed and many Aspen Plus simulations were unsuccessful. After a better estimation of the optimum, the ranges were restricted as follows: feed tray: $7 \ldots 12$; first reactive stage: $7 \ldots 12$; last reactive stage $30 \ldots 50$; total number of stages: $45 \ldots 60$. In this case, more than $95 \%$ of the simulations were successful. The progress of the optimization run is shown in Figure 7.

Figure 6 also shows the process flowsheet, mass balance and the key operating parameters, while Table 4 provides the optimal design parameters of the RD column for DME production. The operating pressure (11.36 bar) leads to reactive stages temperature in the range 130-150 ${ }^{\circ} \mathrm{C}$. The amount of catalyst $(193.2 \mathrm{~kg} / \mathrm{stage})$ occupies $20 \%$ of the stage volume, this being in line with the recommendations for KATAPAK packing (Götze et al., 2001). The reflux ratio, $(6.174 \mathrm{kmol} / \mathrm{kmol})$ ensures the required purity. Along the reactive stages, the liquid-phase methanol mole fraction exceeds $80 \%$, which leads to a large reaction rate. For convenience, Figure 8 plots the temperature and reaction rate profiles while Figure 9 shows the liquid composition profiles along the RD column. Remarkable, for the RD process, the CapEx is only $2395 \mathrm{k} \$$, the OpEx is $2604 \mathrm{k} \$ /$ year, and the specific energy requirements are $2.43 \mathrm{MJ} / \mathrm{kg}$ $(672.5 \mathrm{kWh} / \mathrm{t}) \mathrm{DME}$.

\subsection{Combined gas-phase reactor and reactive distillation}

The main idea of the combined process is to use only the reaction section of existing R-S-R processes for DME production, and include a reactive distillation column in the downstream processing, as shown in Figure 10. This allows complete reactant conversion and avoids the need of recycling. The reactor diameter decreases, but the effect on the TAC is small. However, it should be remarked that the gas-phase reactor of existing DME plants can process more fresh methanol (for example, the R-S-R process illustrated in the previous section could process Figure $2748 \mathrm{kmol} / \mathrm{hr}$ instead of $546 \mathrm{kmol} / \mathrm{hr}$ ). The methanol conversion is eventually driven to completion by the RD column. As the feed to the downstream processing section is not pure methanol (as in the single step RD process), but a ternary mixture (DME, methanol and water from the gas-phase reactor), an additional unit is necessary. Because water has the highest boiling point (and therefore in the RDC column will remain in the liquid phase) and has a detrimental effect on the reaction rate (see equation 3), this component is removed in the first distillation column. The water column was designed for $99 \%$ water recovery, at 99.97 \%wt purity. The methanol - DME mixture is fed above the reactive section of the RDC. In the RD column, the amounts of catalyst (67 kg/stage), is the maximum occupying $20 \%$ of the available space. Despite the higher methanol liquid phase concentration, the reaction rate 
1 is lower compared to the single RD Column process due to less catalyst. Along the reactive stages, the temperature is in the range $134-147{ }^{\circ} \mathrm{C}$. Figure 11 and Figure 12 present temperature, reaction rate and composition profiles along the RD column. Table 5 and Table 6 list the simulation results of the combined process for DME production, while Table 7 provides a summary of the economic results. For the same production capacity (100 ktpy) the cost of the reaction section is lower as compared to the classic R-S-R process due to the absence of the methanol recycle. However, the downstream processing section is somewhat more expensive than the classic direct distillation sequence, as the reaction must also be carried out together with the separation. Moreover, the reactor outlet is not fed as vapor to the RD column (due to the reaction taking place in liquid phase) but as saturated liquid (condensed in the prefractionator). As a consequence, the key economic indicators are slightly increased: CapEx is $3437 \mathrm{k} \$$, OpEx is $3152 \mathrm{k} \$ /$ year and the specific energy requirements are $2.905 \mathrm{MJ} / \mathrm{kg}$ (807 kWh/ton) DME. Nonetheless, the key advantage of this process alternative is that due to the elimination of the methanol recycle, the production capacity could be increased by a factor equal to the reverse of the methanol conversion $\left(1 / X_{\mathrm{MeOH}}\right)$.

\section{Process comparison}

The economic results are summarized for all cases in Table 3 (R-S-R process alternatives), Table 4 (single step process in RD column) and Table 7 (combined process). Based on these figures, it is clear that for a new DME plant the single step process using a reactive distillation column is the best option with the lowest CapEx (about 70\% of the classic R-S-R process) and similar OpEx, with a reduction of $6 \%$ in the specific energy requirements.

However, in case of increasing the capacity of an existing DME plant, it would be cheaper to just revamp the plant by keeping the whole reaction section and reuse the columns of the direct distillation sequence to separate water (first column) and convert the remaining $\mathrm{MeOH}$ to DME (second column, reactive distillation). By doing so, the additional investment is minimized and the TAC reduced in spite of the slight increase in OpEx. Another key advantage of the combined process is possibility to significantly increase the plant capacity due to the absence of the methanol recycle.

\section{Conclusions}

The rigorous process simulations showed that the novel process alternatives based on reactive distillation can significantly improve the classic reactor-separator-recycle process for DME production. Based on the results presented here, the following conclusions can be drawn: 
- The classic reactor-separator-recycle DME process could be improved by feeding the reactor outlet as vapor to the direct distillation sequence (about $8 \%$ savings in TAC).

- The single step process using a reactive distillation column is the most promising for new DME plants due to the lowest CapEx (2395 k\$) and OpEx (2604 k\$/year) - for 100 ktpy plant capacity - as well as specific energy requirements (2.43 MJ/kg DME).

- The combined process (gas-phase reactor + reactive distillation) is not recommended for new plants (due to higher costs than the single step RD process), but it is suitable for revamping existing DME plants. With only a minor additional investment, the plant capacity can be significantly increased by having complete methanol conversion and no recycles, thus allowing a higher processing capacity of the fresh methanol feed.

\section{Acknowledgement}

Financial support of the European Commission through the European Regional Development Fund and of the Romanian state budget, under the grant agreement 155/25.11.2016 (Project POC P-37-449, acronym ASPiRE) is gratefully acknowledged.

\section{References}

1. Agreda V. H., Partin L. R., Heise W. H., High-purity methyl acetate via reactive distillation, Chemical Engineering and Processing, 86 (1990), 40-46.

2. An W., Chuang K., Sanger A., Dehydration of methanol to dimethyl ether by catalytic distillation, Canadian Journal of Chemical Engineering, 82 (2004), 948-955.

3. Arcoumanis C., Bae C., Crookes R., Kinoshita E., The potential of di-methyl ether (DME) as an alternative fuel for compression-ignition engines: A review, Fuel 87 (2008), 10141030.

4. Azizi Z., Rezaeimanesh M., Tohidian T., Rahimpour M. R., Dimethyl ether: A review of technologies and production challenges, Chemical Engineering and Processing: Process Intensification, 82 (2014), 150-172.

5. Bai Z., Ma H., Zhang H., Ying W., Fang D., Process simulation of dimethyl ether synthesis via vapor phase dehydration. Polish Journal of Chemical Technology, 15 (2013), $122-127$.

6. Bai Z., Ma H., Zhang H., Ying W., Fang D., Simulation of a multi-stage adiabatic reactor with inter-stage quenching for dimethyl ether synthesis. Chemical Industry \& Chemical Engineering Quarterly, 20 (2014), 481-490.

7. Berčič G., Levec J., Catalytic dehydration of methanol to dimethyl ether. Kinetic 
1 investigation and reactor simulation, Industrial \& Engineering Chemistry Research, 32 (1993), 2478-2484.

8. Dimian A.C., Bildea C.S., Kiss A.A., Integrated design and simulation of chemical processes, 2nd edition, Elsevier, Amsterdam, 2014.

9. Farsi M., Jahanmiri A., Eslamloueyan R., Modeling and optimization of MeOH to DME in isothermal fixed-bed reactor, International Journal of Chemical Reactor Engineering, 8 (2010), article A79.

10. Götze L., Bailer O., Moritz P., von Scala C., Reactive distillation with KATAPAK®, Catalysis Today, 69 (2001), 201-208.

11. Han Y., Zhang H., Ying W., Fang D., Modeling and simulation of production process on dimethyl ether synthesized from coal-based syngas by one-step method. Chinese Journal of Chemical Engineering, 17 (2009), 108-112.

12. Harmsen J., Process intensification in the petrochemicals industry: Drivers and hurdles for commercial implementation, Chemical Engineering and Processing, 49 (2010), 70-73.

13. Hossenininejad S., Afacan A., Hayes R. E., Catalytic and kinetic study of methanol dehydration to dimethyl ether. Chemical Engineering Research and Design, 90 (2012), 825-833.

14. Huss R.S., Chen F., Malone M.F., Doherty M.F., Computer-aided tools for the design of reactive distillation systems, Computers \& Chemical Engineering, 23 (1999), S955-S962.

15. Ihmels E. C., Lemmon E. W., Experimental densities, vapor pressures, and critical point, and a fundamental equation of state for dimethyl ether, Fluid Phase Equilibria, 260 (2007), 36-48.

16. Kansha Y., Ishizuka M., Song C., Tsutsumi A., Process intensification for dimethyl ether production by self-heat recuperation, Energy, 90 (2015), 122-127.

17. Kiss A.A., Advanced distillation technologies - Design, control and applications. Wiley, Chichester, UK, 2013.

18. Kiss A. A., Bildea C. S., Dimian A. C., Design and control of recycle systems by nonlinear analysis, Computers \& Chemical Engineering, 31 (2007), 601-611.

19. Kiss A. A., Bildea C. S., A review on biodiesel production by integrated reactive separation technologies, Journal of Chemical Technology and Biotechnology, 87 (2012), 861-879.

20. Kiss A. A., Ignat R. M., Revamping dimethyl ether separation to a single-step process, Chemical Engineering \& Technology, 36 (2013), 1261-1267.

21. Kiss A. A., Pragt J. J., Vos H. J., Bargeman G., de Groot M. T., Novel efficient process 
for methanol synthesis by CO2 hydrogenation, Chemical Engineering Journal, 284 (2016), 260-269.

22. Kiss A. A., Suszwalak D. J-P. C., Innovative dimethyl ether synthesis in a reactive dividing-wall column, Computers \& Chemical Engineering, 38 (2012), 74-81.

23. Kookos I.K, Perkins J.D., Control structure selection based on economics: Generalization of the back-off methodology, AIChE Journal, 62(2016), 3056-3064.

24. Lei Z., Zou Z., Dai C., Li Q., Chen B., Synthesis of dimethyl ether (DME) by catalytic distillation, Chemical Engineering Science, 66 (2011), 3195-3203.

25. Li R., Zhang H. T., Ying W. Y., Fang D. Y., Research on the intrinsic kinetics of methanol dehydration to dimethyl ether. Natural Gas Chemical Industry, 39 (2009), 9-12.

26. Luyben W. L., Principles and case studies of simultaneous design, AIChE Wiley, Hoboken, 2011.

27. Malone M., Huss R., Doherty M., Green chemical engineering aspects of reactive distillation, Environmental Science \& Technology, 37 (2003), 5325-5329.

28. Mansouri S. S., Sales-Cruz M., Huusom J. K., Woodley J. M., Gani R., Integrated process design and control of reactive distillation processes, IFAC-PapersOnLine, 48 (2015), 1120-1125.

29. Mollavali M., Yaripour F., Atashi H., Sahebdelfar S., Intrinsic kinetics study of dimethyl ether synthesis from methanol on $\gamma-\mathrm{Al}_{2} \mathrm{O}_{3}$ catalysts, Industrial \& Engineering Chemistry Research, 47 (2008), 3265-3273.

30. Muller M., Hubsch U., Dimethyl ether, in Ullmann's Encyclopedia of Industrial Chemistry, 7th Edition, Wiley-VCH, Weinheim, 2005.

31. Olah G. A., Goeppert A., Surya Prakash G. K., Chemical recycling of carbon dioxide to methanol and dimethyl ether: From greenhouse gas to renewable, environmentally carbon neutral fuels and synthetic hydrocarbons, The Journal of Organic Chemistry, 74 (2009), 487-498.

32. Patrut C., Bildea C. S., Kiss A. A., Catalytic cyclic distillation - A novel process intensification approach in reactive separations, Chemical Engineering and Processing: Process Intensification, 81 (2014), 1-12.

33. Schoenmakers H. G., Bessling B., Reactive and catalytic distillation from an industrial perspective, Chemical Engineering and Processing, 42 (2003), 145-155.

34. Segovia-Hernandez J. G., Hernandez S., Bonilla-Petriciolet A., Reactive distillation: A review of optimal design using deterministic and stochastic techniques, Chemical Engineering and Processing: Process Intensification, 97 (2015), 134-143. 
1 35. Sundmacher K., Kienle A. (Eds.), Reactive distillation: Status and future directions, Wiley-VCH, Weinheim, 2003.

36. Teodorescu M., Rasmussen P., High-pressure vapor-liquid equilibria in the systems

4 nitrogen plus dimethyl ether, methanol plus dimethyl ether, carbon dioxide plus dimethyl ether plus methanol, and nitrogen plus dimethyl ether plus methanol, Journal of Chemical and Engineering Data, 46 (2001), 640-646.

7 37. Turton R., Bailie R.C., Whiting W.B., Shaeiwitz J.A, Analysis, synthesis and design of 8 chemical processes, 3rd edition, Prentice Hall, USA, Appendix A, 2009.

9 38. Wu J. T., Zhou Y., Lemmon E. W., An equation of state for the thermodynamic properties of dimethyl ether, Journal of Physical and Chemical Reference Data, 40 (2011), Article Number: 023104. 


\section{$1 \quad$ Tables}

2

3 Table 1. Simulation results for the reactor-separator-recycle process for DME production 4 (100 ktpy): reaction system (without downstream processing)

5

\begin{tabular}{ll} 
Parameter / unit & Value \\
\hline Reactor & \\
Length / [m] & 12 \\
Diameter / [m] & 1.89 \\
CapEx $[\mathrm{k} \$]$ & 754.48
\end{tabular}

\section{FEHE}

Area / [m]

Duty / [MW]Tab

CapEx $[\mathrm{k} \$]$

41.18

Furnace

Duty [MW]

6.88

CapEx / [k\$]

1006

OpEx / [k\$/year]

1983.7

\section{Steam generator}

Duty / [MW]

0.576

Area / $\left[\mathrm{m}^{2}\right]$

33.3

CapEx / [k\$]

104.1

OpEx / [k\$/year]

$-129.21$ 
1 Table 2. Simulation results for the reactor-separator-recycle process for DME production 2 (100 ktpy): downstream processing (direct distillation sequence)

\begin{tabular}{lll} 
& $\begin{array}{l}\text { DME } \\
\text { Column }\end{array}$ & $\begin{array}{l}\text { Methanol } \\
\text { Column }\end{array}$ \\
\hline Feed condition & & \\
Feed rate $/[\mathrm{kmol} / \mathrm{h}]$ & 667.25 & 394.25 \\
Feed temperature $/\left[{ }^{\circ} \mathrm{C}\right]$ & 170.0 & 86.5
\end{tabular}

\section{Design data}

Number of stages, NT

$18 \quad 30$

Feed stage, NF

$10 \quad 21$

Diameter / [m]

$1.68 \quad 1.16$

Height / [m]

11.6

18.8

Reboiler area / $\left[\mathrm{m}^{2}\right]$

44.5

77.0

Condenser area $/\left[\mathrm{m}^{2}\right]$

681.1

144.7

\section{Operating data}

Distillate rate $/[\mathrm{kmol} / \mathrm{h}]$

273

121.27

Bottoms rate $/[\mathrm{kmol} / \mathrm{h}]$

394.3

273

Reflux ratio

3.94

1.37

Reboiler duty / [MW]

0.625

2.044

Condenser duty / [MW]

6.45

2.82

Condenser pressure / [bar]

10

Distillate purity / [\%wt]

$99.99 \quad 99.95$

Bottoms purity / [\%wt]

-

99.98

\section{Economic data}

$\begin{array}{lll}\text { CapEx / [k\$] } & 911.4 & 601.0 \\ \text { Condenser / [k\$] } & 558.9 & 204.2 \\ \text { Reboiler / [k\$] } & 111.7 & 159.2 \\ \text { Column shell / [k\$] } & 221.6 & 218.2 \\ \text { Trays / [k\$] } & 19.2 & 18.9 \\ & & \\ \text { OpEx / [k\$/year] } & 282.2 & 516.6 \\ \text { Cooling / [k\$/year] } & 133.9 & 58.5 \\ \text { Heating (HP steam] / [k\$/year] } & 148.2 & 458.1 \\ \text { TAC / [k\$/year] } & \mathbf{5 8 6 . 0} & \mathbf{7 1 6 . 9}\end{array}$


2 Table 3. Summary of economic results for the R-S-R process for DME production (100 ktpy)

\begin{tabular}{llll} 
& CapEx / [k\$] & OpEx / [k\$/year] & TAC / [k\$/year] \\
\hline Reactor & 754.5 & - & 251.5 \\
FEHE & 41.2 & - & 13.7 \\
Furnace & 1006.4 & 1983.7 & 2319.2 \\
Steam generator & 104.1 & -129.2 & -94.5 \\
DME column & 910.8 & 281.9 & 585.5 \\
Methanol column & 600.6 & 516 & 716.2 \\
TOTAL & 3417.6 & 2652.4 & 3791.6 \\
& & &
\end{tabular}


2 Table 4. Optimal design parameters of a RD column for DME production (100 ktpy)

\begin{tabular}{|c|c|}
\hline Parameter / unit & Value \\
\hline \multicolumn{2}{|l|}{ Design data } \\
\hline Number of stages, NT & 54 \\
\hline Feed stage, NF & 9 \\
\hline Reactive stages, $\mathrm{NR}_{1}-\mathrm{NR}_{2}$ & $9-42$ \\
\hline HETP / [m] & 0.5 \\
\hline Amount of catalyst / [kg/stage] & 193.2 \\
\hline Catalyst volumetric fraction & 0.2 \\
\hline Diameter / [m] & 2.1 \\
\hline Height / [m] & 28.0 \\
\hline Reboiler area / $\left[\mathrm{m}^{2}\right]$ & 248.8 \\
\hline Condenser area / $\left[\mathrm{m}^{2}\right]$ & 755.0 \\
\hline Feed preheater $/\left[\mathrm{m}^{2}\right]$ & 132.3 \\
\hline \multicolumn{2}{|l|}{ Operating data } \\
\hline Feed rate $/[\mathrm{kmol} / \mathrm{h}]$ & 546 \\
\hline Feed temperature $/\left[{ }^{\circ} \mathrm{C}\right]$ & 85.4 \\
\hline Distillate rate / $[\mathrm{kmol} / \mathrm{h}]$ & 273 \\
\hline Bottoms rate $/[\mathrm{kmol} / \mathrm{h}]$ & 273 \\
\hline Reflux ratio & 6.177 \\
\hline Reboiler duty / [MW] & 8.485 \\
\hline Condenser duty / [MW] & 9.148 \\
\hline Feed preheater / [MW] & 0.943 \\
\hline Condenser pressure / [bar] & 11.36 \\
\hline Distillate purity / [\%wt DME] & 99.99 \\
\hline Bottoms purity / [\%wt water] & 99.97 \\
\hline \multicolumn{2}{|l|}{ Economic data } \\
\hline CapEx / [k\$] & 2394.9 \\
\hline Condenser / [k\$] & 597.6 \\
\hline Reboiler / [k\$] & 342.2 \\
\hline Column shell / [k\$] & 578.4 \\
\hline Packing / [k\$] & 586.5 \\
\hline Catalyst / [k\$] & 65.7 \\
\hline Trays / [k\$] & 31.9 \\
\hline Feed pre-heater & 192.6 \\
\hline OpEx / [k\$/year] & 2604.2 \\
\hline Cooling / [k\$/year] & 189.7 \\
\hline Heating (HP steam] / [k\$/year] & 2414.5 \\
\hline TAC / [k\$/year $]$ & 3402.5 \\
\hline
\end{tabular}


1 Table 5. Simulation results for the combined gas-phase reactor and reactive distillation 2 process for DME production (100 ktpy): gas-phase reactor section

Parameter / unit

\section{Reactor}

Length / [m]

Diameter / [m]

CapEx $[\mathrm{k} \$]$

\section{FEHE}

Area / [m]

Duty / [MW]

CapEx [k\$]

\section{Furnace}

Duty [MW]

CapEx / [k\$]

OpEx / [k\$/year]

\section{Steam generator}

Duty / [MW]

Area / $\left[\mathrm{m}^{2}\right]$

CapEx [k\$]

OpEx [k\$/year]
Value

12

1.71

231.8

11.8

1.981

7.65

5.63

848.66

1671.55

0.366

25.1

86.54

$-82.08$

3 
1 Table 6. Simulation results for the combined gas-phase reactor and reactive distillation process for DME production (100 ktpy): downstream processing section

Parameter / unit

Feed rate $/[\mathrm{kmol} / \mathrm{h}]$

Feed temperature $/\left[{ }^{\circ} \mathrm{C}\right]$

\section{Design data}

Number of stages, NT

Feed stage, NF

Reactive stages

Diameter / [m]

Height / [m]

Reboiler area / $\left[\mathrm{m}^{2}\right]$

Condenser area $/\left[\mathrm{m}^{2}\right]$

Catalyst / [kg/stage $]$

Catalyst volumetric fraction [\%]

\section{Operating data}

Distillate rate / $[\mathrm{kmol} / \mathrm{h}]$

Bottoms rate / $[\mathrm{kmol} / \mathrm{h}]$

Reflux ratio

Reboiler duty / [MW]

Condenser duty / [MW]

Condenser pressure / [bar]

Distillate purity / [\%wt]

Bottoms purity / [\%wt]

\section{Economic data}

CapEx / [k\$]

Condenser / [k\$]

Reboiler / [k\$]

Column shell / [k\$]

Trays / [k\$]

Packing / [k\$]

OpEx / [k\$/year]

Cooling / [k\$/year]

Heating (HP steam] / [k\$/year]

TAC / [k\$/year]

\section{Water-column RD column}

546

324.8

$164.2 \quad 66.6$

18

35

98

- $8-25$

1.25

$\begin{array}{ll}1.38 & 21.8\end{array}$

$112 \quad 90.8$

$1066 \quad 386.4$

$\begin{array}{ll}1066 & 67\end{array}$

$\begin{array}{ll}- & 0.2\end{array}$

324.8

273

221.2

51.8

1.867

1.937

1.727

3.159

7.118

3.822

5

10.2

0.003 (Water),

0.9999 (DME)

0.9997 (Water)

0.9997 (Water)

1143.8

956.7

747.9

386.8

203.6

177.8

177.5

270.2

14.8

13.3

108.6

556.6

1006.7

79.3

927.4

409.0

1325.6 
1 Table 7. Summary of economic results for the combined gas-phase reactor and reactive

2 distillation process for DME production (100 ktpy)

\begin{tabular}{llll} 
& CAPEX / [k\$] & OPEX / [k\$/year] & TAC / [k\$/year] \\
\hline Reactor & 231.8 & - & 77.3 \\
FEHE & 7.65 & - & 2.55 \\
Furnace & 848.67 & 1671.55 & 1954.44 \\
Steam generator & 86.54 & -82.08 & -53.23 \\
Water column & 936.8 & 556.6 & 868.86 \\
RD Column & 1325.6 & 1006.7 & 1448.56 \\
TOTAL & $\mathbf{3 4 3 7 . 0 6}$ & $\mathbf{3 1 5 2 . 7 7}$ & $\mathbf{4 2 9 8 . 4}$ \\
& & &
\end{tabular}


1 Figure captions (auto-updated)

2

Figure 1. Residue curve map and ternary diagram of the mixture DME-MeOH- $\mathrm{H}_{2} \mathrm{O}$ at 10 bar

Figure 2. Reactor-separation-recycle process for DME production

Figure 3. TAC vs reactor-inlet temperature, for reactors with various lengths. Total annual cost, pressure drop and reactor-outlet temperature are indicated, for each optimal point.

Figure 4. Methanol conversion versus temperature, at fixed reaction rate.

Figure 5. T-Q curve of the feed-effluent heat exchanger (FEHE), for two different values of the cold stream outlet temperature.

Figure 6. Single step process using a reactive distillation column for DME production

Figure 7. Progress of the RDC optimization

Figure 8. Temperature and reaction rate profile along the RD column

Figure 9. Liquid (continuous line) and vapor (dashed line) composition profiles along the RD column

Figure 10. Combined gas-phase reactor and reactive distillation process for DME production

Figure 11. Temperature and reaction rate profiles along the RD column, in the combined gasphase reactor and RDC process

Figure 12. Liquid (continuous line) and vapor (dashed line) composition profiles along the $\mathrm{RD}$ column, in the combined gas-phase reactor and RDC process 

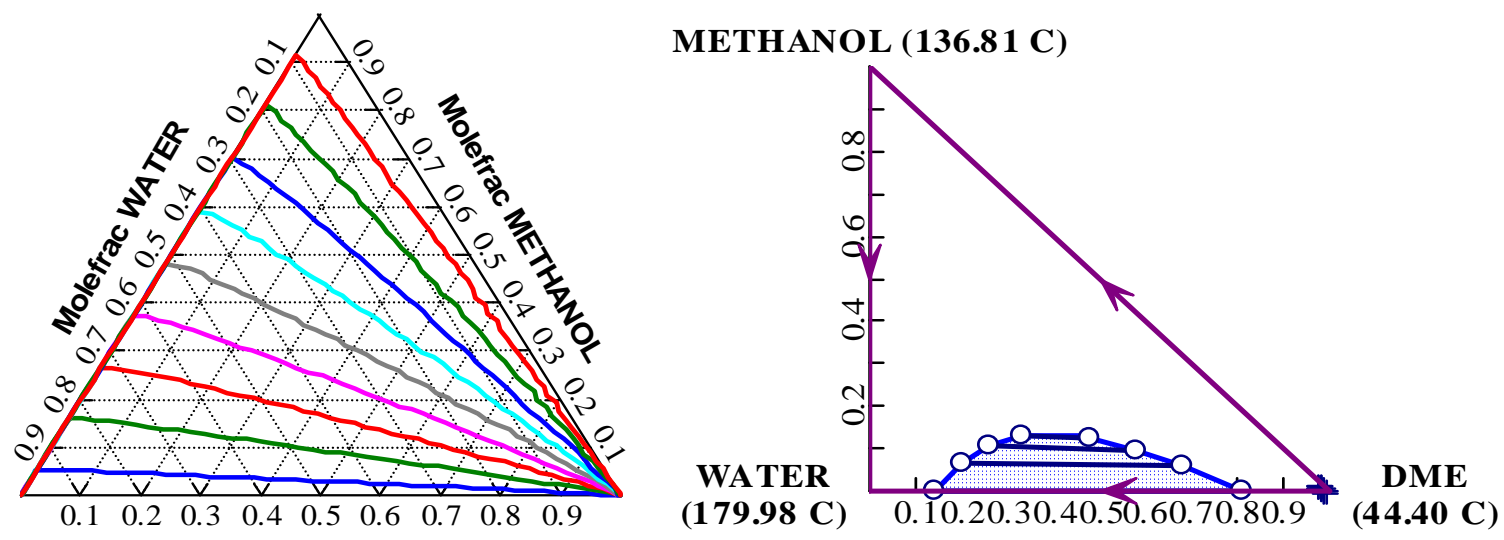

Molefrac DME

Figure 1. Residue curve map and ternary diagram of the mixture DME-MeOH- $\mathrm{H}_{2} \mathrm{O}$ at 10 bar 5

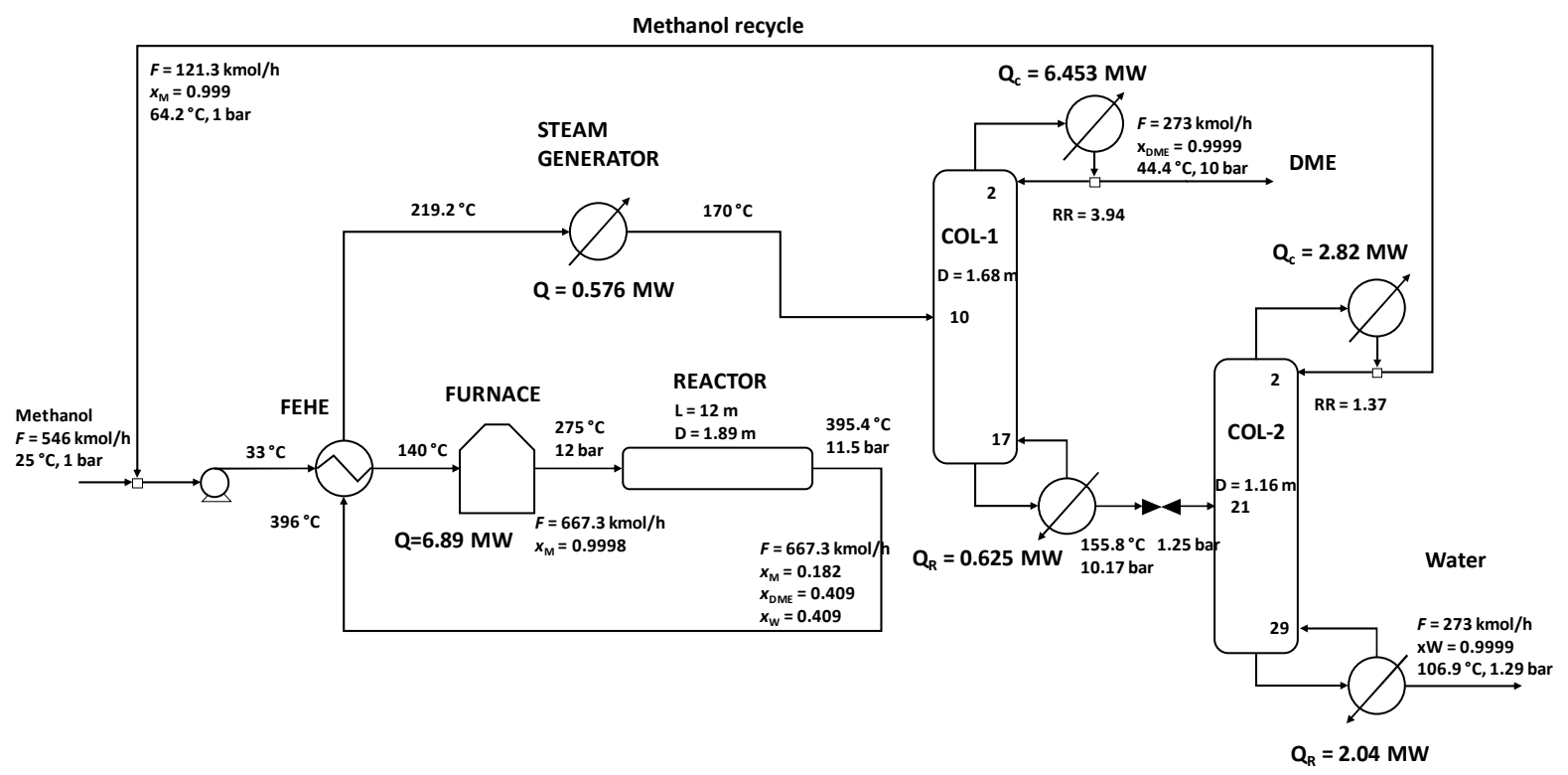




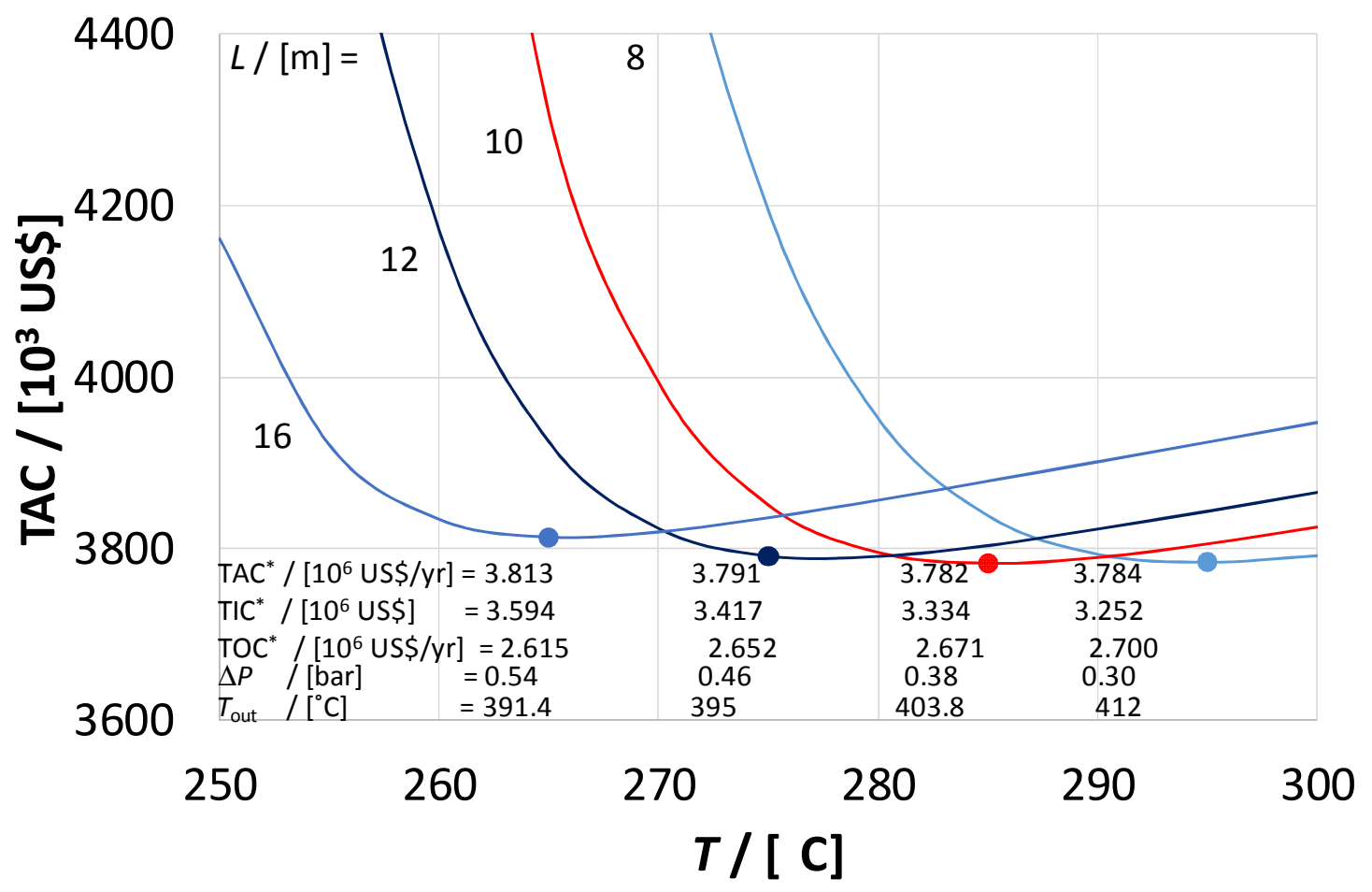

Figure 3. TAC vs reactor-inlet temperature, for reactors with various lengths. Total annual cost, pressure drop and reactor-outlet temperature are indicated, for each optimal point.

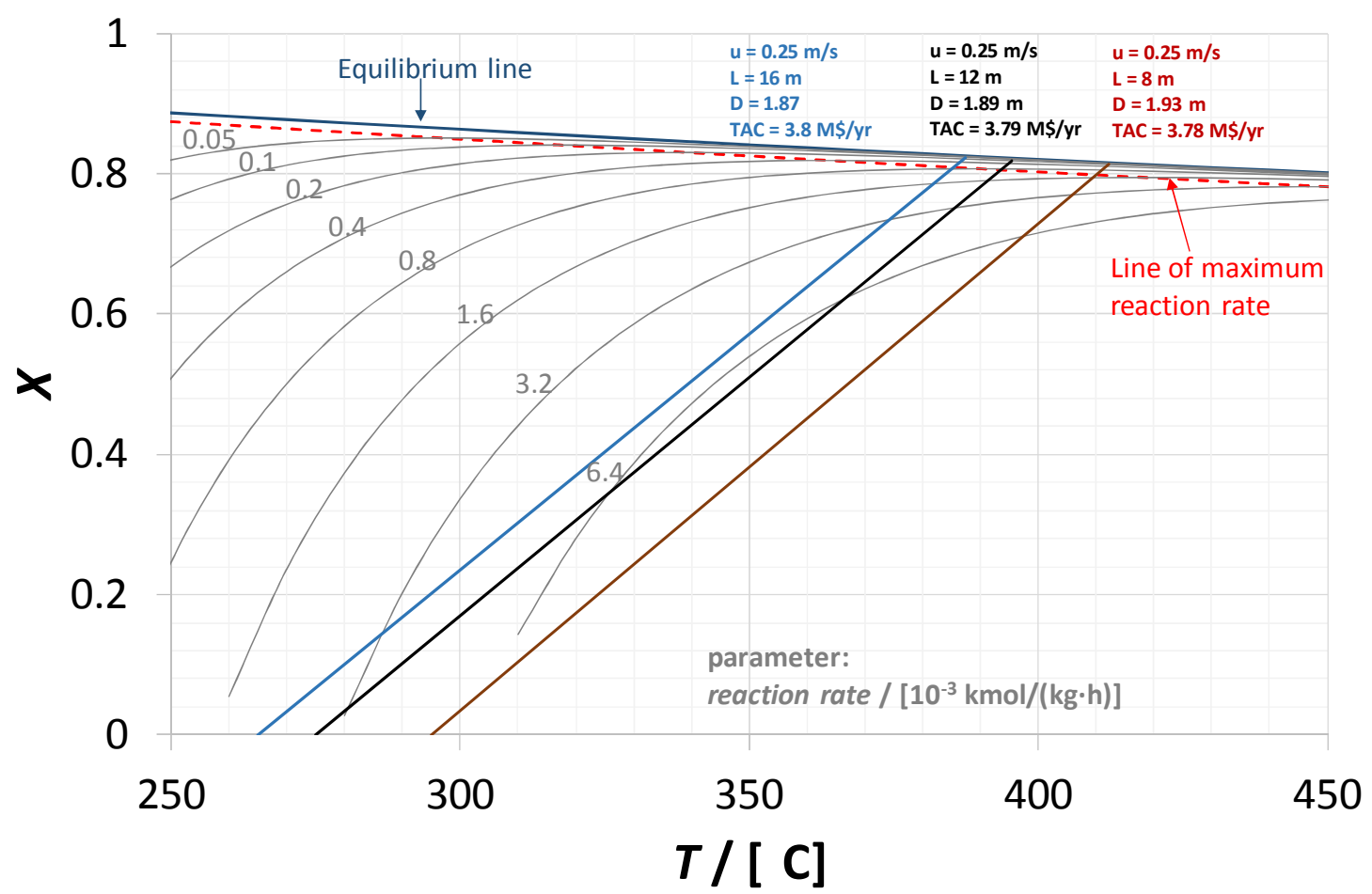

Figure 4. Methanol conversion versus temperature, at fixed reaction rate. 

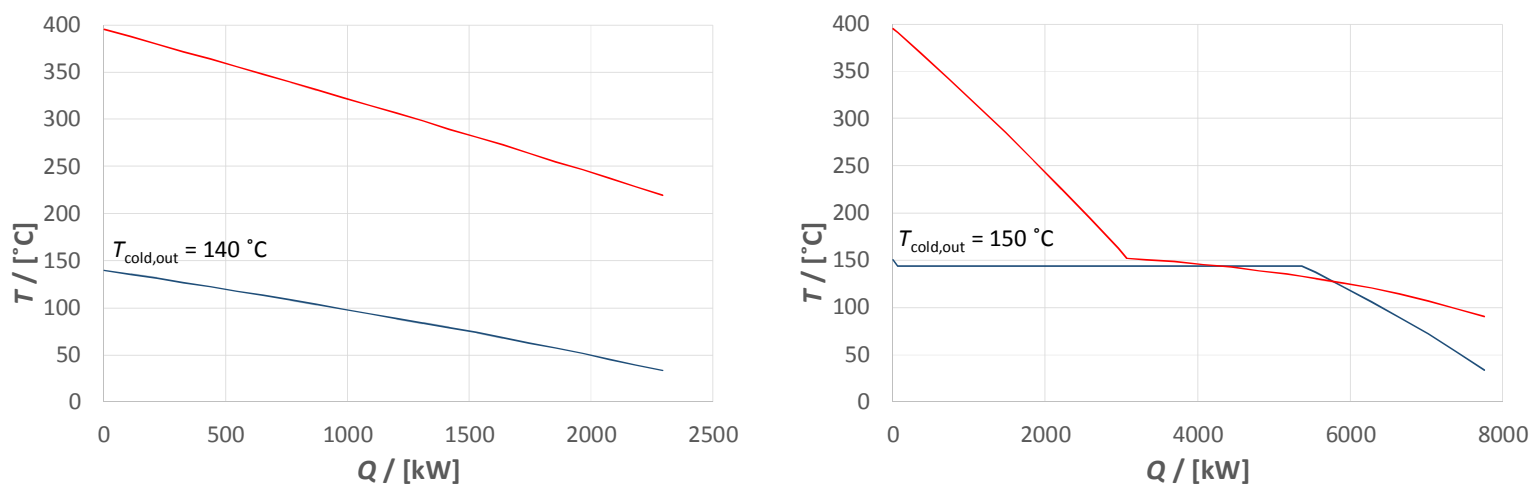

Figure 5. T-Q curve of the feed-effluent heat exchanger (FEHE), for two different values of the cold stream outlet temperature.

5

6

7

8

9

10

11

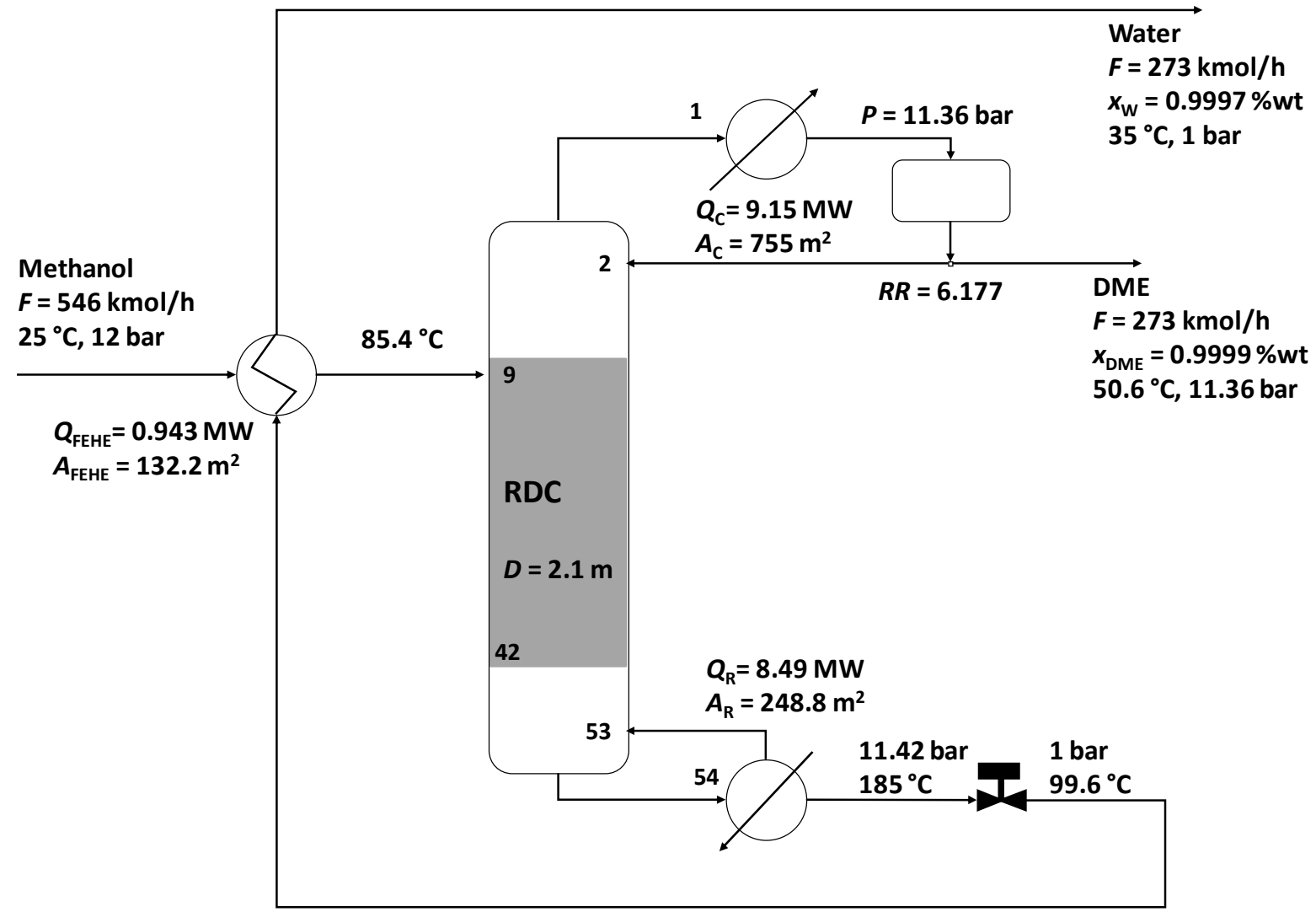

Figure 6. Single step process using a reactive distillation column for DME production 


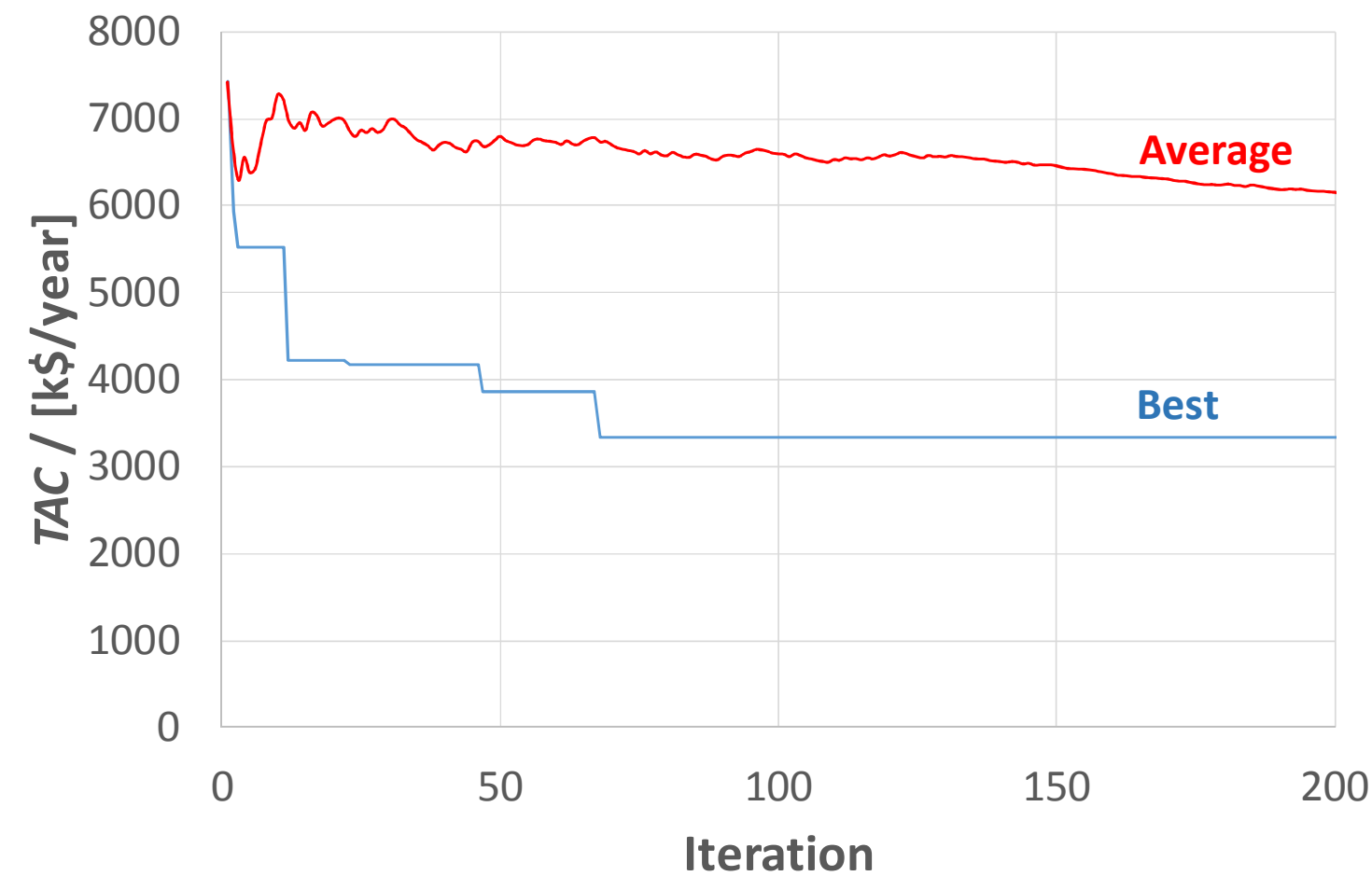

Figure 7. Progress of the RDC optimization

4

5
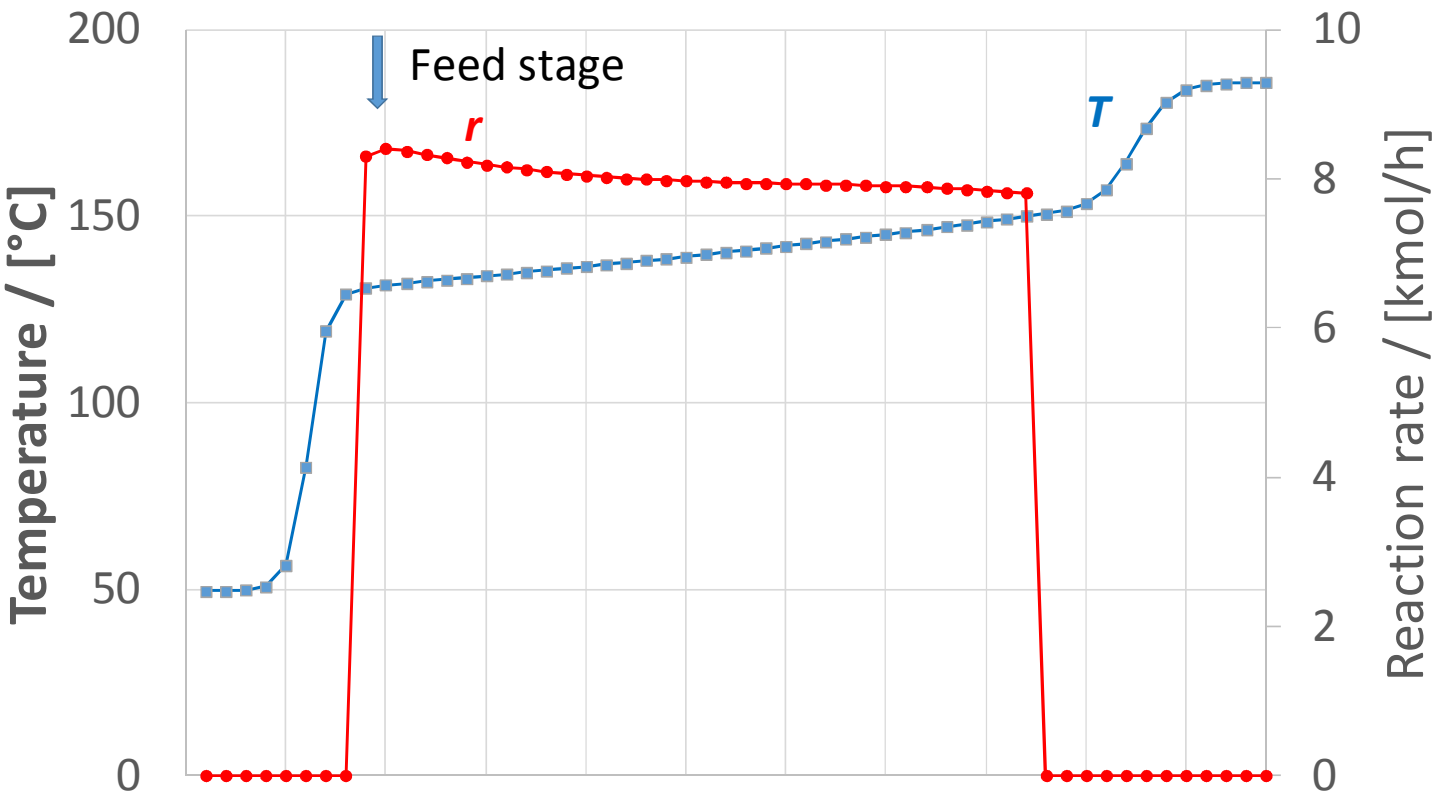

$\begin{array}{lllllllllll}0 & 5 & 10 & 15 & 20 & 25 & 30 & 35 & 40 & 45 & 50\end{array}$

Stage

Figure 8. Temperature and reaction rate profile along the RD column 


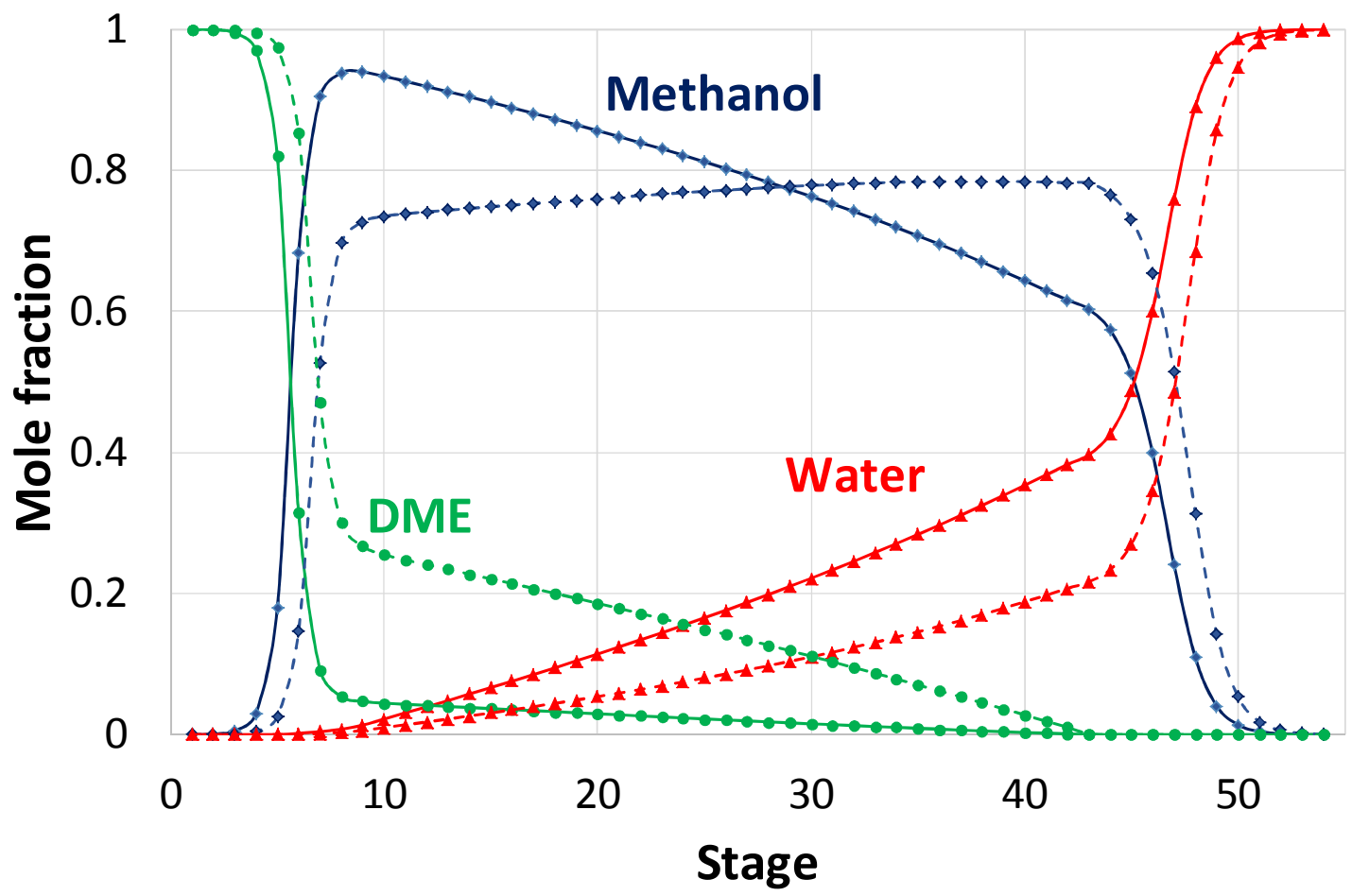

Figure 9. Liquid (continuous line) and vapor (dashed line) composition profiles along the RD 4 column

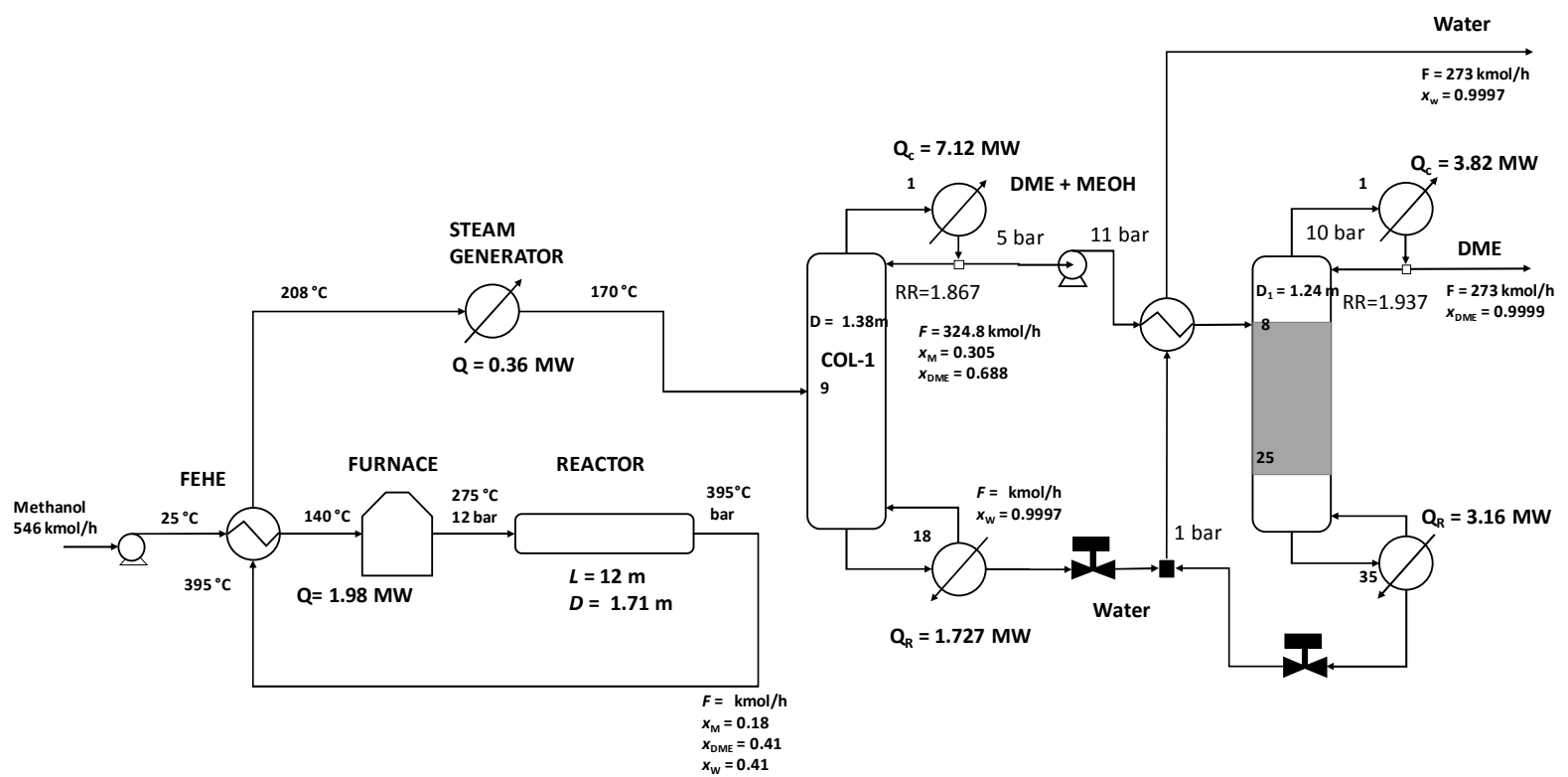

Figure 10. Combined gas-phase reactor and reactive distillation process for DME production 


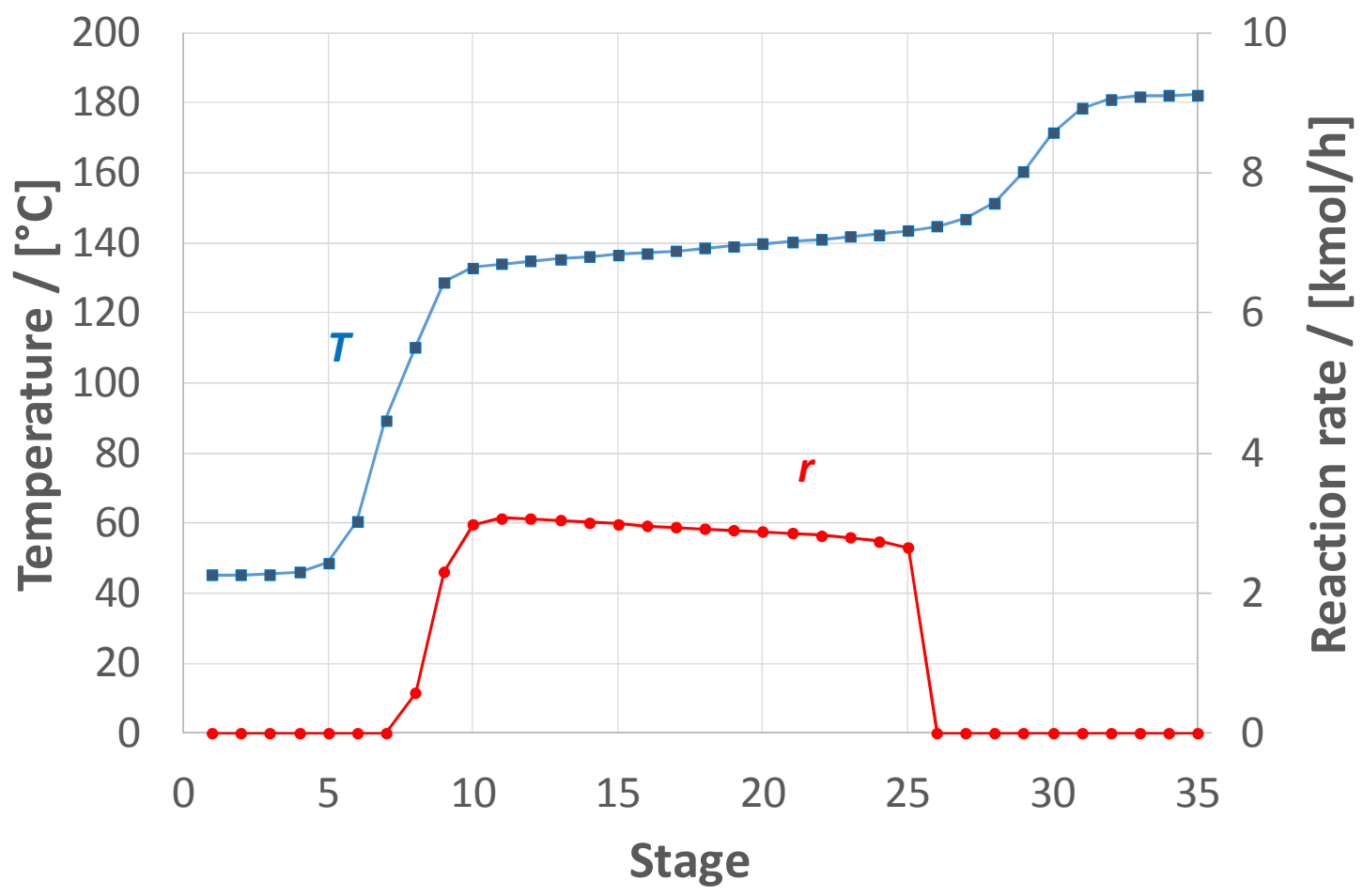

Figure 11. Temperature and reaction rate profiles along the RD column, in the combined gasphase reactor and RDC process

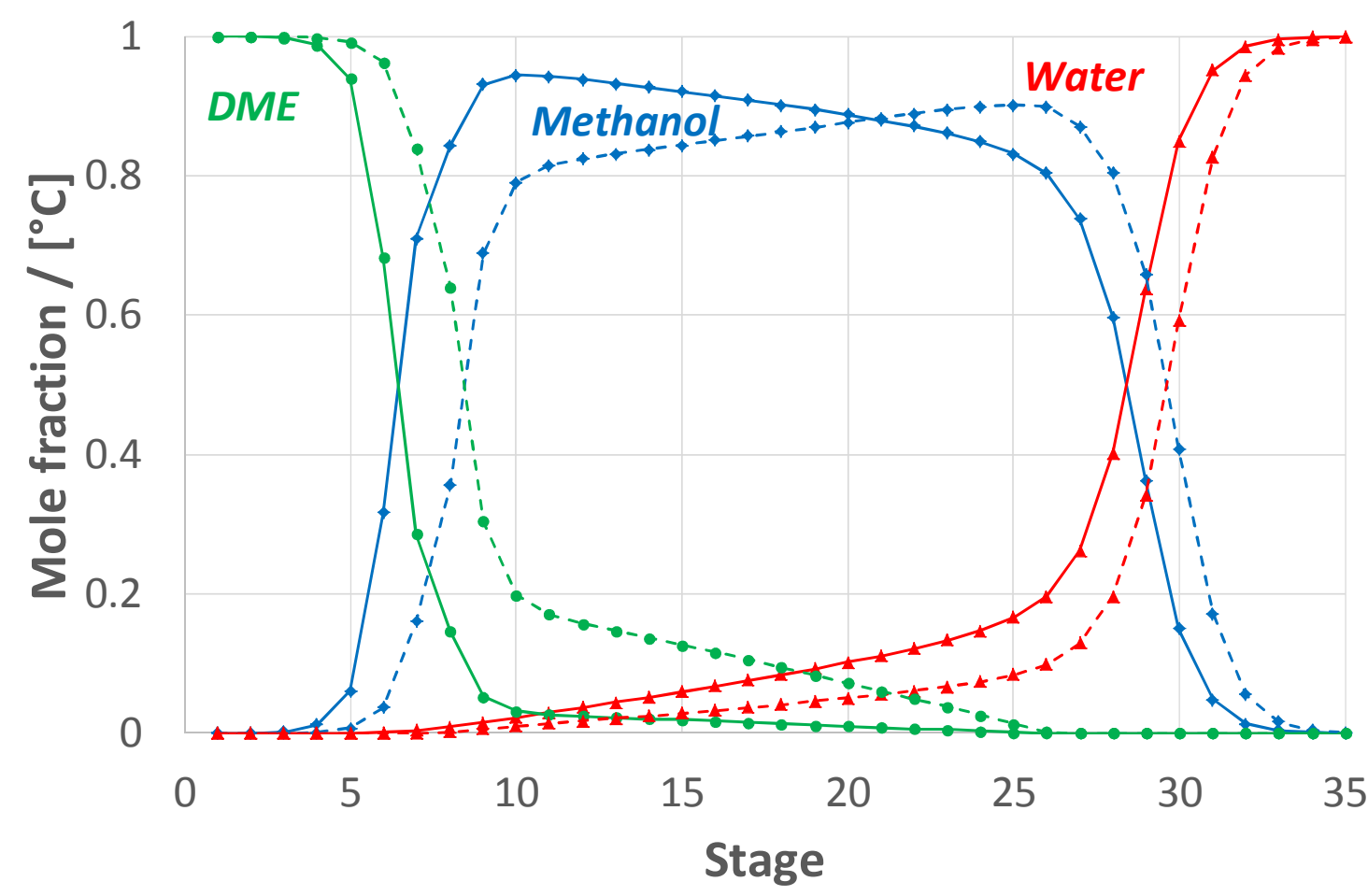

Figure 12. Liquid (continuous line) and vapor (dashed line) composition profiles along the 